\title{
Arqueologia do Arraial do Cabo - com foco nos sítios da Ilha do Cabo Frio*
}

\author{
Maria Cristina Tenório* * \\ Marisa Coutinho Afonso *** \\ Diogo de Cerqueira Pinto ***
}

\begin{abstract}
TENÓRIO, M.C.; AFONSO, M.C.; PINTO, D.C. Arqueologia do Arraial do Cabo com foco nos sitios da Ilha do Cabo Frio. Revista do Museu de Arqueologia e Etnologia, São Paulo, 20: 127-145, 2010.
\end{abstract}

Resumo: O município do Arraial do Cabo, estado do Rio de Janeiro, apresenta um interessante conjunto arqueológico, notável por sua concentração no espaço e pela diversidade dos locais escolhidos para os assentamentos. Foram identificados sitios arqueológicos localizados sobre dunas, em praias de mar aberto ou voltadas para lagunas, em elevações superiores a $50 \mathrm{~m}$ acima do nivel do mar, em abrigos, em ilhas e em pequenas enseadas protegidas. Com os objetivos de saber se a ocupação de diferentes ambientes está relacionada à presença de diversas unidades culturais, entender a dinâmica da ocupação do espaço, a relação intersitios e os motivos para a concentração de sitios observada, foram procuradas as características principais de cada sitio e a história de sua construção.

Palavras-chave: Sambaqui - Arraial do Cabo - Cultura material - Contatos - Trocas.

\section{Introdução}

$\mathrm{E}$ ste trabalho tem por objetivo apresentar os resultados das pesquisas desenvolvidas no Arraial do Cabo, a norte do município do Rio de Janeiro, e também contribuir com subsídios para a discussão sobre o caráter insular das ocupações pré-históricas em ilhas.

Para a delimitação da identidade cultural dos responsáveis pelos sitios encontrados na localidade do Arraial do Cabo, utilizaram-se como ferramentas para a abordagem a identificação dos elementos mais característicos da $\left(^{*}\right)$ As pesquisas no Arraial do Cabo contaram com o apoio da Fundação de Amparo à Pesquisa do Estado do Rio de Janeiro - FAPERJ e do Conselho Nacional de Desenvolvimento Científico e Tecnológico - CNPq, entidade governamental brasileira promotora do desenvolvimento cientifico e tecnológico, e também fizeram parte das atividades de pós-doutorado desenvolvido no Museu de Arqueologia e Etnologia - MAE/USP. $\left.{ }^{* *}\right)$ Museu Nacional da Universidade Federal do Rio de Janeiro-UFRJ. <ctenorio@domain.com.br> (***) Museu de Arqueologia e Etnologia da Universidade de São Paulo. <marisa.afonso@usp.br>

$\left.{ }^{* * * *}\right)$ Mestre em Arqueologia pelo Museu Nacional da Universidade Federal do Rio de Janeiro-UFRJ.

<falecomdiogo@hotmail.com> 
cultura material encontrada nos sitios, o processo de formação dos assentamentos e o confronto com os dados obtidos em outra área de estudo, a Ilha Grande, localizada no litoral sul do Rio de Janeiro.

Embora exista um periodo em que os dois locais são habitados, a Ilha Grande foi ocupada em um momento de expansão das ocupações litorâneas; já no Arraial do Cabo, o momento do aumento demográfico parece corresponder a um periodo de retração da cultura sambaquiana.

Enquanto na Ilha Grande encontra-se uma ocupação distante do continente, mas no centro de vários ambientes muito ricos em recursos alimentares, no Arraial do Cabo o padrão de ocupação caracteriza-se pela presença não apenas de sítios localizados próximos aos recursos, como também de outros localizados em locais inóspitos, longe dos recursos minimos para a manutenção de um grupo permanente.

Na Praia de Massambaba, no Arraial do Cabo, encontra-se um dos conjuntos de sitios mais extensos do litoral do Rio de Janeiro. A extensão da ocupação possui mais de 500 metros de linha de praia, constituindo uma área que, em determinadas épocas, teria sido densamente ocupada. Levando-se em consideração que parte do periodo de sua ocupação coincide com as datas de $1.740 \mathrm{AP}, 2.200 \mathrm{AP}$ e $2.600 \mathrm{AP}$, obtidas para a entrada dos grupos Tupi no estado do Rio de Janeiro (Buarque 1999: 321; Buarque et al. 2003: 50), ), e acrescentando-se o fato de que foram encontradas cerâmicas pertencentes a essa tradição nas dunas da praia, é possivel trabalhar com a hipótese de que essa concentração de pessoas poderia indicar uma estratégia defensiva a grupos adventicios. Esta hipótese é corroborada pelo fato de que, nesse periodo, diminui sensivelmente o número de sítios na costa (Tenório 1998: 243), aumentando os localizados em ilhas e em pontas que, provavelmente, na época de sua ocupação, estavam separados do continente, como se houvesse uma fuga para locais mais protegidos e um abandono de locais que antes eram os mais procurados por grupos pré-ceramistas. Andrade Lima (1991: 638) também leva em consideração a possibili- dade de ter havido uma mudança no padrão de assentamento com a chegada dos ceramistas ao litoral e propõe que a ocupação da Ilha de Santana, localizada no litoral norte do estado do Rio de Janeiro, local mais protegido e com menor oferta de alimentos, pode ter sido consequência desse contato.

\section{Arraial do Cabo}

A cidade do Arraial do Cabo se encontra $280 \mathrm{~km}$ a norte da Ilha Grande, na parte centro-sul do litoral do estado do Rio de Janeiro, região Sudeste do Brasil. Segundo Carvalho (2000: 204), a localidade sofre a influência da "Ressurgência", fenômeno que se caracteriza pela subida de águas frias, ricas em nutrientes (ACAS - Água Central do Atlântico Sul, de $18^{\circ} \mathrm{C}$ ).

A região (Fig. 1) tem a forma de uma pequena península e é cercada por um cordão de 30 quilômetros de praias arenosas, tendo ao centro um complexo rochoso denominado Morro do Atalaia. Apresenta também formações lacustres - destacando-se a Lagoa de Araruama - onde predominam exuberantes dunas e vegetação própria das restingas (Gurgel 1992: 27).

A topografia é caracterizada por um relevo cristalino mais modesto do que o maciço litorâneo que se estende da cidade de Niterói para leste. Em termos geológicos, a área de restinga, que cobre $90 \%$ do municipio, é uma planície marinha resultante da acumulação de sedimentos quaternários. Esta planície se estende entre o mar e as lagunas, ao longo de toda a costa sul, com cordões arenosos apoiados em elevações de rochedos e morros que apresentam altitudes elevadas para a região. O relevo é de promontórios convexos formados por rochas metamórficas, ortognaisses característicos do chamado Complexo Cabo Frio. Já a ilha é constituida de rochas alcalinas hipo-abissais em intrusão por evento magmático que gerou também brechas e diques que se distribuem ao longo da ilha e principalmente no flanco sudeste, segundo Ferrari (2001). O clima no Arraial 


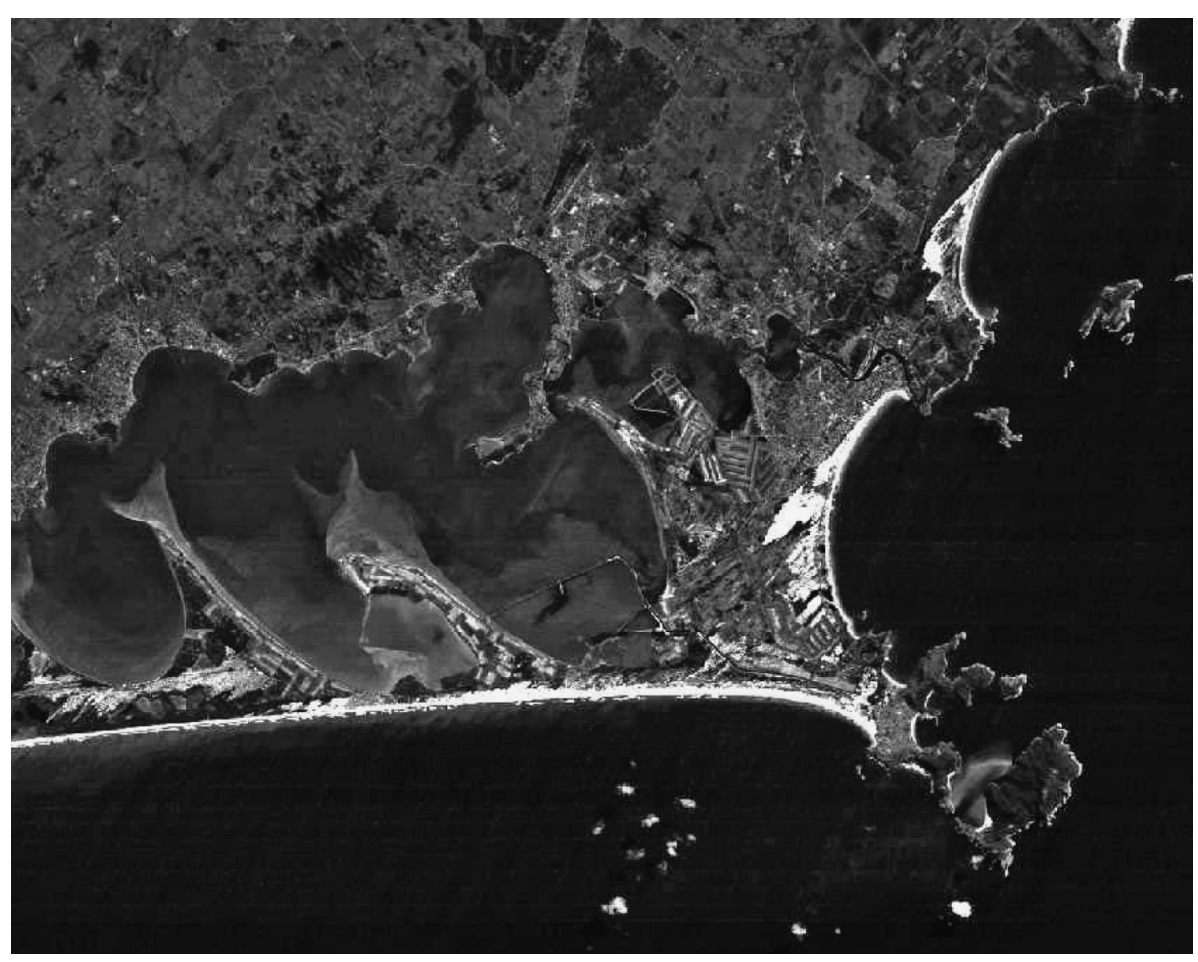

Fig. 1. Arraial do Cabo (INPE Landsat 2000).

do Cabo é semi-árido, definido por Barbiére (1984: 84), e a precipitação é de $750 \mathrm{~mm}$ ao ano. Apresenta duas estações: o inverno, que vai de junho a setembro, com o domínio dos ventos sul e sudoeste, e de periodos frios e chuvosos; e o verão, de outubro a março, quando predominam os ventos leste e nordeste e a situação de ressurgência é quase permanente.

A Lagoa de Araruama, a mais extensa desse trecho do litoral, limita-se ao sul com a praia da Massambaba, uma grande restinga com $50 \mathrm{~km}$ de extensão E-O.

A vegetação está caracterizada por vários ecossistemas: restingas, manguezais, brejos, lagoas e morros.

\section{Contexto arqueológico}

Foram identificados 20 sítios, sendo que: cinco estão localizados sobre dunas em praias de mar aberto (sitios Ponta da Cabeça, Colônia de Pesca, Massambaba I, Massambaba II,
Massambaba III); três estão em elevações superiores a $50 \mathrm{~m}$ acima do nível do mar (sitios Condominio do Atalaia, Boqueirão e Usiminas); dois estão em ilha, sendo que um sobre dunas e um em elevação superior a 50 metros (sitio Ilha do Cabo Frio e Usiminas, já citado anteriormente); quatro em abrigos em alturas de mais de 30 metros (Caverna do Boqueirão, Abrigo sob Rocha do Atalaia, Abrigo da Praia dos Anjos e Abrigo da Praia do Forno); cinco estão localizados em pequenas enseadas (Praia dos Anjos, Praia do Forno I e II, Praia do Pontal e Prainha); e dois estão localizados sobre dunas próximos a lagunas (Salinas Sal Neve e Duna da Figueira).

Além desses sitios foram encontrados três conjuntos de amoladores-polidores fixos: amoladores-polidores fixos da Praia Grande I e II e do Diogo. Localizados no costão de praia de mar aberto, podem estar tanto associados a sítios situados a mais de 40 metros de altura (Sítio Ponta da Cabeça) como também aos localizados sobre dunas. 


\section{Sítios pesquisados}

Até o momento, já foram pesquisados os sítios Colônia de Pesca (Mendonça de Souza et al. 1983/84), Massambaba, Caverna do Boqueirão (Machado et al. 1989a e 1989b), Ponta da Cabeça (Tenório et al. 1992), Condominio do Atalaia (Tenório 2002), Boqueirão, Ilha do Cabo Frio e Usiminas (Tenório et al. 2005 e Tenório et al. 2009) (Fig. 2).

Os sítios Colônia de Pesca, Massambaba I, II e III, Ponta da Cabeça e Condomínio do Atalaia estão localizados na Praia de Massambaba. Os quatro primeiros foram construidos sobre dunas, a cerca de 200 metros da linha de maré média atual. Já os dois últimos estão em locais mais elevados: o sítio Ponta da Cabeça, no Morro do Atalaia, estendendo-se sobre uma duna escalonar consolidada a cerca de 40 metros de altura; e o Condominio do Atalaia, sobre o embasamento cristalino (Complexo Cabo Frio), a 55 metros de altura. O sitio do Boqueirão está localizado no mesmo Morro do Atalaia, também a 55 metros acima do nivel do mar; e, defronte a ele, está a Ilha do Cabo Frio, com os sitios Ilha do Cabo Frio e Usiminas, o primeiro sobre as dunas da praia apresenta parte submersa, o segundo também a uma altura elevada, 53 metros acima do nivel do mar.

A área de ocupação do sítio da Ponta da Cabeça (Tenório et al. 1992 : 279) tem cerca de $1.700 \mathrm{~m}^{2}$ e sua extensão, somada aos sítios
Colônia de Pesca (Mendonça de Souza et al. 1983/84: 107) e dunas de Massambaba I, II e III, (Machado et al. 1989a: 429 e 1989b: 447), perfaz 500 metros de linha de praia, constituindo uma área que, em determinadas épocas, teria sido densamente ocupada.

A praia de Massambaba (Fig. 3), onde também estão localizados os amoladorespolidores fixos do Arraial do Cabo, apresenta o mesmo conjunto de assentamento verificado na Ilha Grande (Tenório 1992: 292) e em outros locais, como em Armação de Búzios (Tenório e Gaspar 1990) e em Cabo Frio, no estado do Rio de Janeiro, e no Pântano do Sul (Rohr 1977), em Florianópolis, Santa Catarina. Ou seja, são sitios sobre duna relacionados a sítios localizados em locais mais altos que apresentam camadas malacológicas bem definidas.

\section{Massambaba}

O sitio Massambaba (RJ-JC-56) foi pesquisado pela equipe do Instituto de Arqueologia Brasileira (IAB), em 1973, quando foram retirados dez enterramentos simples e um duplo, que tinham por acompanhamento funerário artefatos líticos, ósseos e adornos de pedra e concha. Este sítio está localizado sobre dunas e apresenta cerâmica Tupi e também uma cerâmica escura sem decoração em sua superficie. A camada arqueológica, de coloração amarelada, composta por restos orgânicos, tem $60 \mathrm{~cm}$ de espessura média.

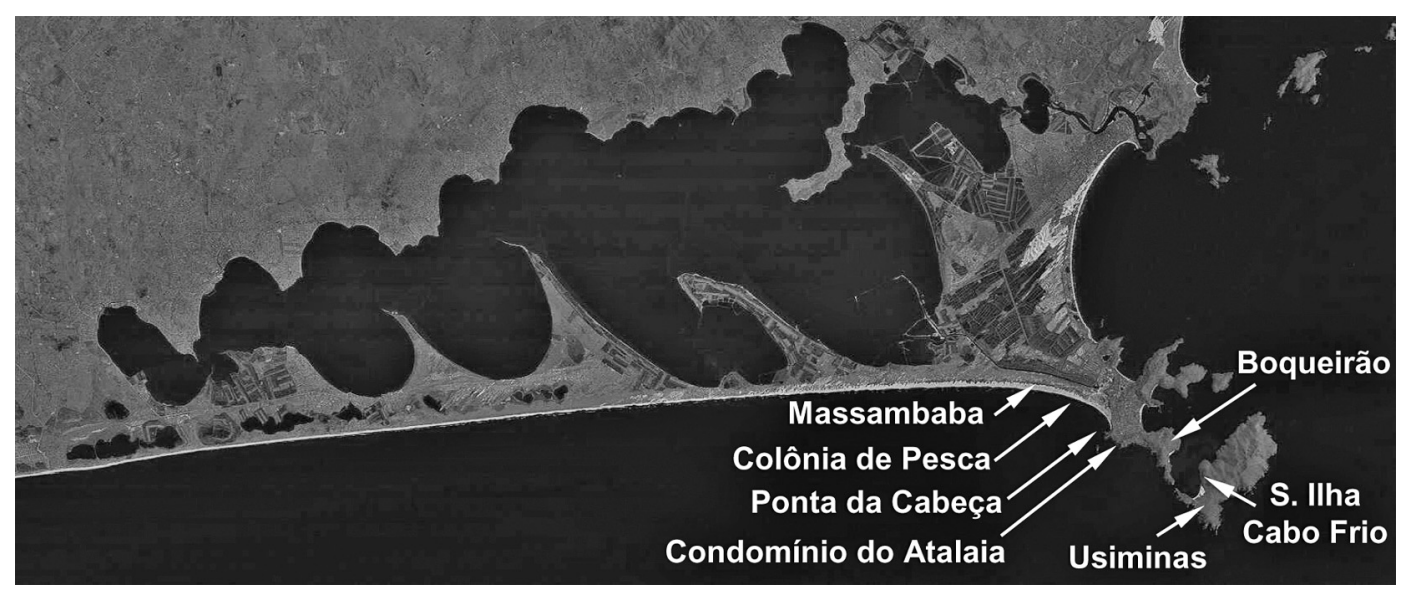

Fig. 2. Arraial do Cabo e a localização dos sitios. 


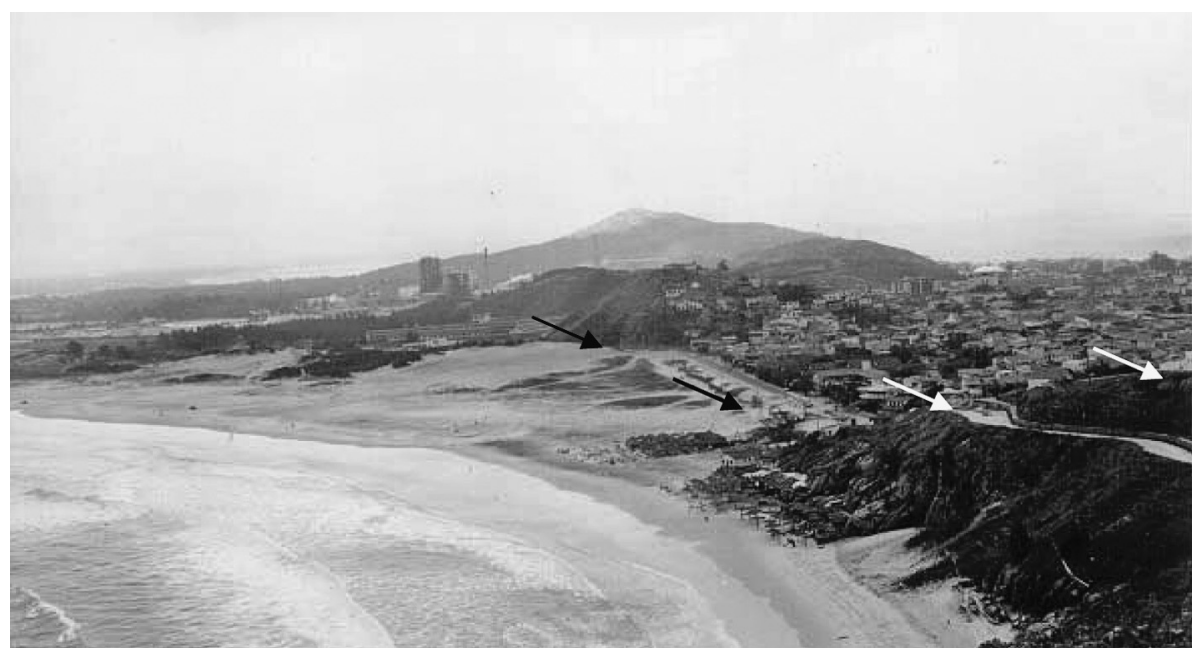

Fig. 3. Concentrações de sítios - praia de Massambaba.

Segundo Machado et al. (1989b: 453), a situação estratigráfica dos esqueletos sugere contemporaneidade e não se descarta a possibilidade de se tratar de um enterramento coletivo decorrente de morte ocasionada por atividades guerreiras ou por doenças especificas.

Dos enterramentos que se pôde verificar a posição em que foram depositados, três esqueletos estavam estendidos e apenas um fletido, sendo que todos os estendidos estavam em decúbito ventral. Chamam a atenção três enterramentos, dois masculinos e um feminino, que tinham a face voltada para o chão, fato também verificado em dois sepultamentos no sitio Usiminas.

Dois casos de individuos masculinos, com idade acima de 30 anos, tinham pedaços de corante próximo às mãos. Em um deles o corante chegou a tingir a areia, enquanto o outro tinha também uma espátula óssea como acompanhamento, sendo este artefato descrito como "peça acanalada, ponta aguçada irregularmente" (Machado et al. 1989b: 452).

Dos que se pôde verificar o sexo e a idade, cinco são masculinos. Destes, três tinham mais de 30 anos. Quatro são mulheres, também com mais de 30 anos, sendo que uma tinha mais de 50 anos quando faleceu. Também foi identificada uma criança com idade entre sete e oito anos.

Destacam-se dois artefatos que acompanhavam um enterramento do sexo feminino: um adorno em fragmento de Conus sp, de forma trapezoidal, com duas perfurações na porção superior; e um pingente de gnaisse polido, triangular, com os cantos e extremidades arredondadas e perfuração na extremidade oposta.

\section{Colônia de Pesca}

A única publicação relacionada a este sítio, a de Mendonça de Souza et al. (1983/84), apresenta resultados preliminares de pesquisa e tem como enfoque principal a questão da paleonutrição. Na publicação, o sítio é descrito como uma ocupação sobre duna relacionada a grupos essencialmente pescadores, já que são raras as carapaças de moluscos presentes. Os artefatos não são descritos, sendo apenas mencionada a presença de dentes de cação perfurados. Relacionada a essa informação, chama a atenção o fato de que, embora tivessem sido encontrados dentes provenientes de nove espécies, só os dentes de individuos das espécies Prionace glauca, Negaprion sp e Galeocerdo $s p$ foram utilizados para a elaboração dos artefatos, provavelmente usados como adorno. Esses objetos também são encontrados nos sitios Ponta da Cabeça e Condomínio do Atalaia, Ilha do Cabo Frio e Usiminas.

No sítio Colônia de Pesca, cabe destacar a presença de enterramentos em covas cônicas, 
onde o individuo era depositado sentado, em posição fetal e cercado de ocre.

\section{Sítio Ponta da Cabeça}

O sítio da Ponta da Cabeça apresenta três camadas de ocupação que totalizam $1,70 \mathrm{~m}$ de camada arqueológica.

A primeira camada é menos densa que as posteriores e é constituída por pequenas fogueiras acesas em reentrâncias do terreno, contendo lascas de quartzo, artefatos ósseos e restos de moluscos, e está datada em $3.270 \pm 70$ anos AP. A ocupação teve seu início no topo do morro, a cerca de 40 metros de altura, estando a base do sítio sobre uma camada argilosa de coloração vermelha alaranjada.

Na segunda camada de ocupação, as fogueiras são maiores e formam uma continua camada escura de $40 \mathrm{~cm}$ de espessura, contendo restos de peixes e moluscos, lascas de quartzo e pontas elaboradas em osso. Nesta camada também foi encontrado o enterramento de uma criança de seis anos, sepultada em decúbito lateral esquerdo.

A terceira camada está datada em $2.080 \pm$ 40 anos AP (Scheel-Ybert 1998: 112), quando a ocupação teria sido mais intensa, resultando em um adensamento da camada arqueológica. É também quando restos de madeira encontrados no mangue aumentam visivelmente (Scheel-Ybert 1998: 141); no entanto, não se sabe se um manguezal teria se formado próximo ao sitio ou se seus habitantes, por causa do aumento de população, tiveram de explorar ambientes mais distantes. De qualquer maneira, nesse periodo a ocupação já se estende pela duna que se apóia na encosta, aumentando a área plana do morro.

É no final do segundo momento de ocupação e início do terceiro que ocorre um aumento no consumo de moluscos, sendo que, até então, os grupos responsáveis pela construção do sítio eram essencialmente pescadores. Os moluscos mais consumidos são a Astraea sp, a Olivancillaria sp, o Thaumastus sp, o Megalobulimus sp e a Pinctada imbricata (Röding 1798), que passam a predominar nos niveis superiores. $\mathrm{Da}$ pesca, destacam-se a enxova (Pomatomidae) e o sargo de dentes (Sparidae), assim como os restos ósseos de animais de grande porte, como cações (Lamidae, Cachahrinidae), raias (Dasyatidae) e mamiferos marinhos. $\mathrm{O}$ consumo de peixes aumentou consideravelmente no início do terceiro momento de ocupação, quando também foram consumidos ouriços e vegetais, representados por coquinhos calcinados. Como instrumentos, foram identificados seixos percutores, raspadores e lâminas de machado, além de lascas de quartzo hialino de excelente qualidade.

A indústria óssea está representada por grande quantidade de pontas, dentes perfurados, vértebras trabalhadas e por espátulas. Como matéria-prima para a elaboração das pontas, os ossos de mamiferos foram os mais usados, seguidos dos de raias e dos de aves.

São também encontradas valvas de moluscos apresentando desgaste por uso, trabalhadas e também carapaças perfuradas, sendo estes artefatos característicos dos sítios Boca da Barra (Barbosa 1999: 133) e Salinas Peroano (Franco e Gaspar 1992: 162), localizados no canal de Itajuru, a cerca de $9 \mathrm{~km}$ de distância pela linha da costa. As valvas de bivalves trabalhadas são artefatos marcantes no sítio Boca da Barra, que tem sua base datada em $3.760 \pm 180$ anos AP.

As carapaças de Olivancillaria sp com perfurações no dorso aparecem nos últimos niveis de ocupação $(0-40 \mathrm{~cm})$ do Sitio Salinas Peroano, cuja base fica a $140 \mathrm{~cm}$ de profundidade e está datada em $4.340 \pm 70$ AP.

A quarta camada indica um momento de declínio da ocupação: ela é de coloração mais clara, apresenta bolsões de restos malacológicos e foram encontrados cinco fragmentos cerâmicos sem decoração, não identificados.

\section{Sítio Condomínio do Atalaia}

Este sítio está localizado a 50 metros acima do nivel do mar, longe de fontes d'água potável e dos recursos alimentares, porém do lado de um veio de quartzo de excelente qualidade. $\mathrm{O}$ sítio Condomínio do Atalaia (Fig. 4) está a 370 metros do sítio Ponta da Cabeça, a 400 metros do Colônia de Pesca e a 570 metros dos sítios Massambaba II e III. 


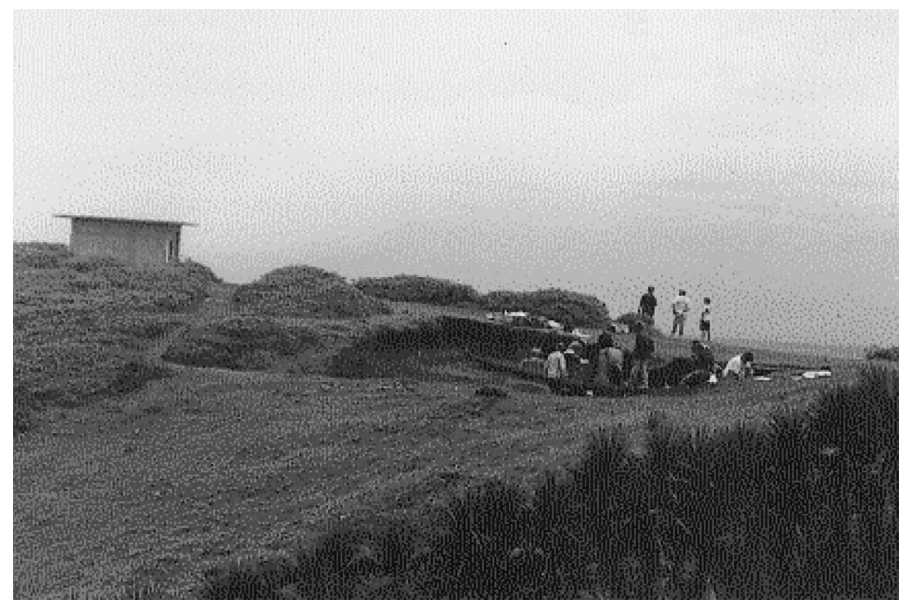

Fig. 4. Sitio Condominio do Atalaia.

O sítio apresenta três camadas de ocupação: a primeira, em cuja base foram obtidas duas datações - $4.190 \pm 130 \mathrm{AP}$ e $4.120 \pm 110$ AP -, é caracterizada pela presença de pisos de argila, fogueiras e um enterramento; a segunda, pela presença apenas de quartzo lascado e restos de indústria litica de quartzo de excelente qualidade proveniente da fonte de matériaprima existente ao lado do sítio; e a terceira, com a antiguidade de $1.690 \pm 90 \mathrm{AP}$, volta a ter as caracteristicas que indicam ter sido um local usado predominantemente para realizar enterramentos. Foram encontrados nove enterramentos primários, além de uma área contendo fragmentos de ossos humanos calcinados e carvão associado.

Segundo Rodrigues-Carvalho et al. (2005: 142), dos nove enterramentos relacionados à última ocupação, dois são de crianças com menos de cinco anos e sete são de adultos. Desses, seis apresentam sinais de periostite extensa nos membros inferiores, alguns com espessamento da superfície óssea, especialmente nas tibias. A prevalência dessas lesões, somadas ao fato de o sitio não favorecer a habitação, sugere a possibilidade de enterramento diferencial ou, ainda, a persistência de um padrão peculiar de saúde ao longo da ocupação do sítio.

Na primeira ocupação predominaram os alimentos obtidos em praias de enseadas. Já na terceira, foram trazidos principalmente de praias abertas ou de locais de águas profundas, cuja captura teria exigido o uso de embarcações, como o caso do Galeocerdo cuvieri que habita águas quentes próximo a ilhas, tendo sido, provavelmente, pescados com utilização de embarcações fora da Praia de Massambaba. Nessas duas ocupações, há o predominio de raias, tubarões e enchova. A diferença na distribuição dos animais utilizados está na presença de macacos, tatus, baleia e do baiacu, apenas na primeira ocupação, e de caranguejo, preá, ouriço, tartaruga e do robalo, apenas na terceira.

Nas duas ocupações foram consumidas predominantemente as mesmas espécies de moluscos: a Astraea lapistina (Philippi 1844), o Thaumastus sp e Megalobulimus sp, sendo a primeira - e a mais consumida - coletada em costões de enseadas, e as últimas, terrestres.

Outras espécies foram utilizadas em bem menor quantidade, podendo-se destacar a Anadara notabilis (Röding 1798), a Ostrea sp e a Anomalocardia brasiliana (Gmelin 1791), que só aparecem relacionadas à primeira ocupação, e o Cerithiun atratum (Born 1778) e o Strombus costatus (Gmelin 1791), que são encontrados só na terceira ocupação. Em menor quantidade e pouco representadas nas duas ocupações, são as valvas de Lucina pectinata (Gmelin 1791) e de Olivancillaria sp.

O único enterramento relacionado à primeira ocupação foi encontrado cercado por valvas de Anadara notabilis, que ocorrem também dentro de uma fogueira acesa numa reentrância próxima, cavada no piso, juntamente com ossos articulados de boto.

Como já foi mencionado, os responsáveis pela segunda camada de ocupação não levaram alimentos para o sítio. É provável que esta ocupação corresponda a estadas curtas, apenas o tempo suficiente para a retirada e o processamento do material litico, cuja semelhança com o encontrado no sitio Ponta da Cabeça permite que se 
proponha que os responsáveis pela segunda ocupação sejam os mesmos construtores desse sítio. Essa hipótese é corroborada pela existência de um "caminho" com restos de lascamento de quartzo entre os dois sitios.

Dos artefatos encontrados, destacam-se os elaborados a partir de ossos. Além de espátulas, vértebras e dentes perfurados, foram encontradas 502 pontas ósseas elaboradas a partir de esporão de raia (78\%), ossos de peixes $(11,9 \%)$, ossos de aves $(6,9 \%)$ e, em menor escala, cascos de tartaruga (3,2\%). São pontas e bipontas, definidas em nove tipos, segundo a morfologia e técnica de fabricação, que predominam na terceira ocupação e estão concentradas nas áreas dos enterramentos. Chama a atenção a presença de 16 pontas de forma espatulada, elaboradas a partir de osso de tartaruga, pouco recorrente nos sitios localizados no litoral do Rio de Janeiro, estando todas associadas a um enterramento múltiplo. Até então, essas pontas só haviam sido encontradas associadas a enterramentos no sitio Geribá I, em camada datada em $1.480 \pm 90$ AP (Tenório et al. 1990: 88), e no sítio Pontinha, em camada superior à camada datada em $1.790 \pm 40 \mathrm{AP}$ (Kneip e Machado 1993: 46).

Foram encontradas também oito espátulas e seis furadores com morfologia semelhante aos encontrados no sítio Ponta da Cabeça e ao associado a um enterramento no sítio Massambaba I (Machado et al. 1989a) (Fig. 5).

\section{Sítio do Boqueirão}

Seguindo o Morro do Atalaia na direção do boqueirão que separa o continente da Ilha do Cabo Frio, encontramos o sítio do Boqueirão, localizado a 53 metros acima do nivel do mar, em local distante das fontes de recursos alimentares e da água potável. A área recebe impacto do vento nordeste e do sudoeste na virada do tempo. Apresenta excelente visibilidade - avista-se toda a entrada do boqueirão: a
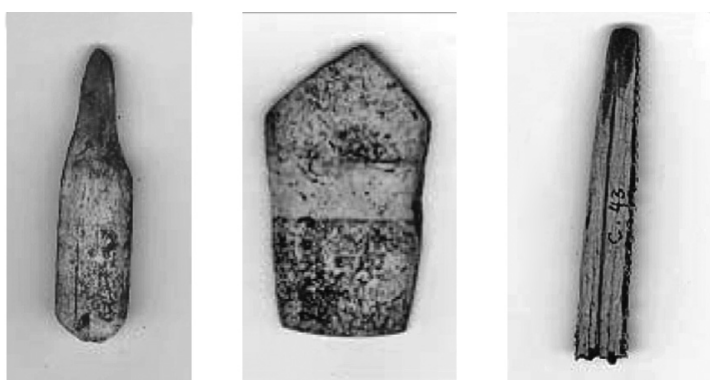

Fig. 5. Artefatos ósseos encontrados no sitio Condomínio do Atalaia (da esquerda para direita) ponta óssea elaborada a partir de osso de peixe; furador; ponta elaborada a partir de osso de tartaruga; ponta elaborada a partir de esporão de raia.

sul, a Ilha de Cabo Frio e

os sítios Ilha do Cabo Frio e Usiminas; e a norte, a ilha do Francês e a ponta do Morro do Atalaia, onde está localizado o sitio do Condominio. Trata-se de um sítio raso, com uma profundidade média de $50 \mathrm{~cm}$, e apresenta três manchas de ocupação.

Foi constatada a presença de duas camadas. A mais recente é mais compacta e continua, com $40 \mathrm{~cm}$ de espessura, composta de carapaças de Thaumastus sp e Astrea sp, fragmentos de ossos de peixe de médio e de pequeno porte, espículas de ouriço e coquinhos calcinados. Também são encontradas manchas de fogueiras e artefatos, como lascas de quartzo, pontas ósseas elaboradas a partir de esporão de raia com serra retirada, furadores em osso, dentes de cação perfurado. Encontram-se também restos de indústria litica, pedaços de ocre, pequenos seixos rolados associados a grandes blocos de pedras. A segunda camada, mais antiga, apresenta a mesma composição, porém é menos compacta e o material arqueológico só ocorre nas fogueiras. Estas circundam um enterramento de uma mulher com menos de 30 anos (Fig. 6). O sepultamento foi feito em posição fletida lateral esquerda, com a cabeça orientada para noroeste, a face para nordeste e os pés para sudeste. Está cercado por pedras e por pequenas fogueiras, estando as maiores no peito e nas costas, onde aparecem grandes pedaços de carvão. Os ossos mais queimados se encontram próximos à região dos joelhos. Perto do esqueleto foram encontrados bivalves marinhos, os únicos encontrados no sítio. 


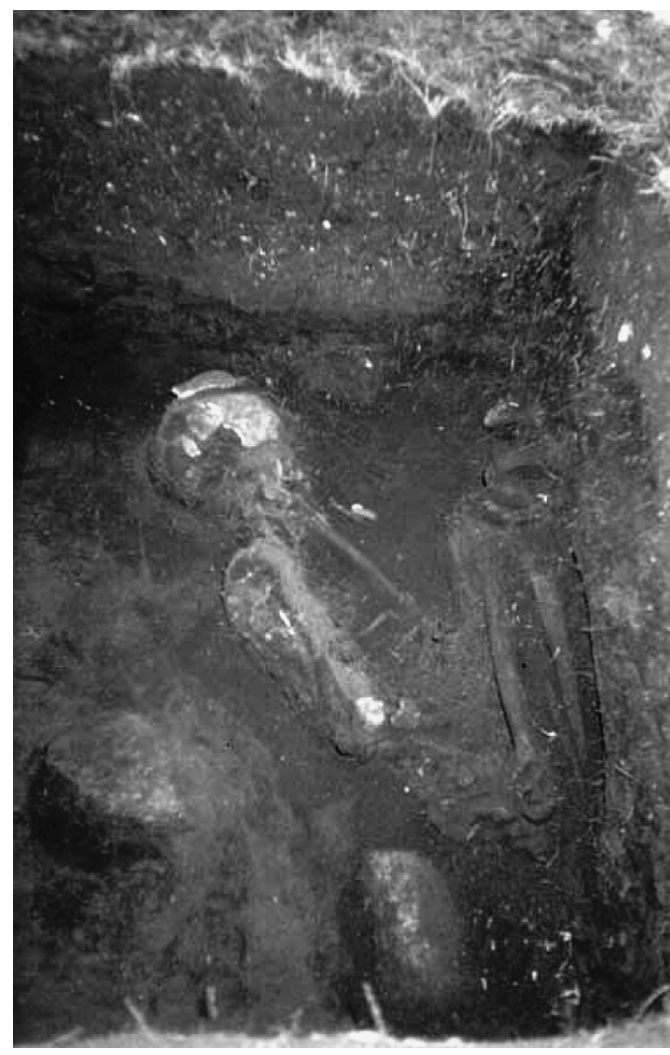

Fig. 6. Enterramento no sitio do Boqueirão.

Dois eventos podem ser observados na área escavada. O primeiro, no momento inicial da ocupação, caracterizado pela presença de um enterramento cujo ritual envolvia o acendimento de fogueiras onde os alimentos eram processados. No segundo, mais recente e que corresponde à camada I datada em 1.623 \pm 32 anos AP (Angulo et al. 2007: 4), percebe-se uma aglomeração de um número maior de pessoas durante um periodo mais longo.

A localização deste sítio se assemelha à do Sítio Condominio do Atalaia (Fig. 7), lugar muito alto onde não são encontradas fontes de água potável ou de alimentos. Os dados obtidos até o momento sugerem que a formação desses dois sitios está relacionada à sua função como ponto estratégico de vigia e como local para a realização de rituais.

\section{Caverna do Boqueirão}

Cerca de 20 metros abaixo do sítio do Boqueirão, em local de difícil acesso por estar no meio de um penhasco, encontra-se uma caverna com $2 \mathrm{~m}$ de altura e $5 \mathrm{~m}$ de profundidade, que foi denominada sítio Caverna do Boqueirão (RJ-JC-57) (Machado et al. 1989b). Dela, a equipe do Instituto de Arqueologia Brasileira retirou enterramentos secundários de dois individuos femininos, com cerca de 35 anos, e dois masculinos, com idade média de 25 anos associados a material litico.

Segundo os autores, as caracteristicas dos restos ósseos sugerem que o ritual mortuário incluiu um repositório temporário em outro local, possivelmente sob o solo, onde teriam ficado um tempo suficiente para permitir a decomposição da carne e tornar os ossos desarticulados.

Embora os autores não tenham se aprofundado na questão da relação desses individuos com populações pré-históricas litorâneas, a localização do sítio, os desgastes dentários observados nos esqueletos e a ausência de urnas cerâmicas parecem indicar uma relação com o sitio do Boqueirão. É provável que os rituais e os enterramentos primários fossem realizados neste sítio antes de serem levados para a Caverna do Boqueirão.

\section{Sítio Usiminas}

O sítio Usiminas está localizado numa área plana, no topo de uma duna escalonar consolidada, a 53 metros acima do nivel do mar e apresenta uma área elipsoidal de $1.920 \mathrm{~m}^{2}$. A área mais ocupada apresenta camadas bem definidas que somam $160 \mathrm{~m}$ de espessura. $\mathrm{O}$ sítio está a cerca de $800 \mathrm{~m}$ de distância do sítio Ilha do Cabo Frio.

O local, embora distante das fontes de recursos alimentares, oferece excelente visibilidade e está próximo de uma formação de rocha magmática boa para lascar e para produzir instrumentos pouco resistentes para corte. Análises sedimentológicas demonstraram a presença de um corpo d'água próximo ao sítio (Tenório e Villagran 2009: 144). Dele, se avistam os sítios Ilha do Cabo Frio, Boqueirão, o oceano e a entrada da barra.

Nas duas quadrículas abertas, uma de $4 \mathrm{~m}^{2}$ na área central e outra de $2 \mathrm{~m}^{2}$ no limite norte 


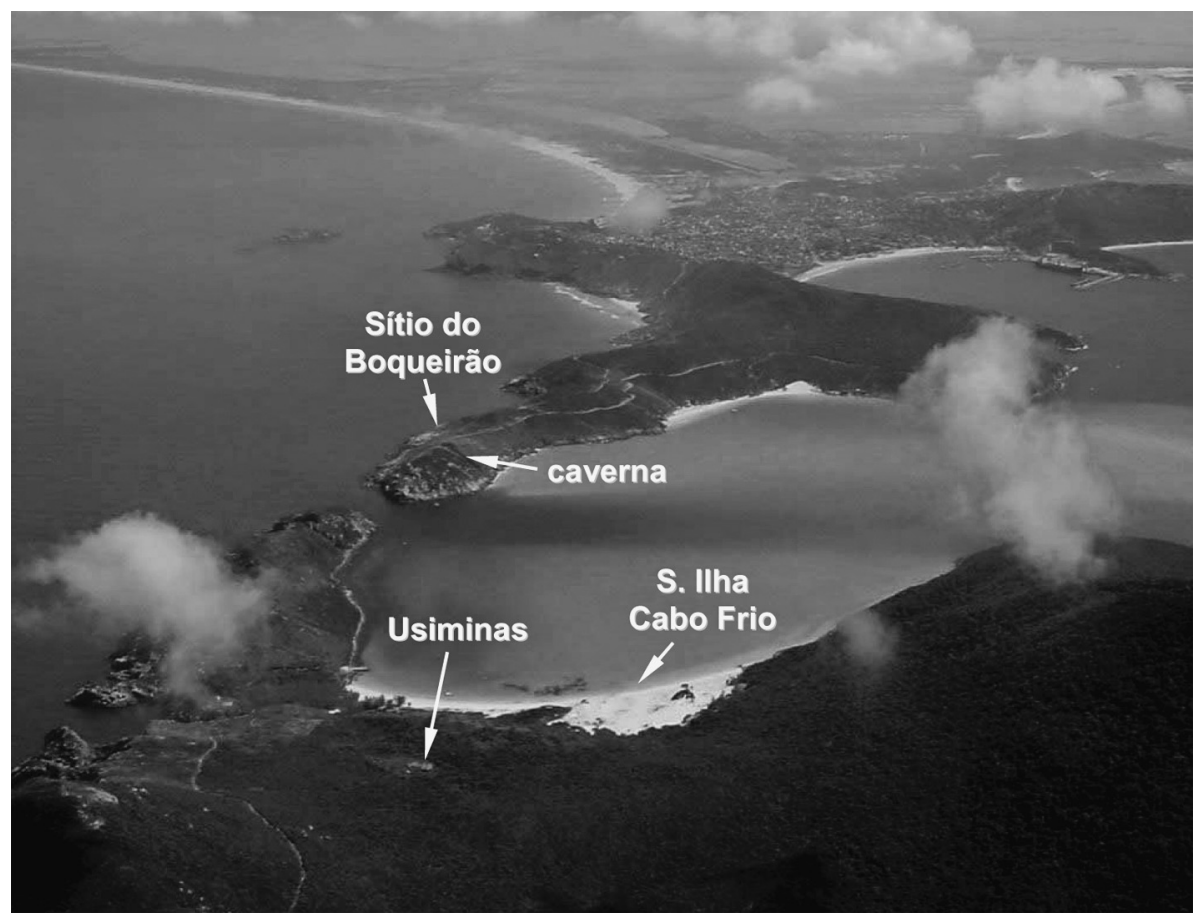

Fig. 7. Boqueirão e os sitios.

da área plana com o declive da duna, foram encontradas seis camadas arqueológicas.

\section{Descrição das camadas}

1 a Camada arqueológica superficial de coloração cinza, contendo fragmentos de concha, de restos de peixe e material intrusivo, camada alterada por obras de aplainamento do terreno;

$2^{a}$ Camada cinza mais clara, constituida do mesmo material arqueológico, porém em menor quantidade;

3a Camada de areia branca estéril;

$4^{a}$ Camada de areia branca acinzentada, com pouco material;

$5^{\text {a }}$ Camada malacológica com espessura média de $60 \mathrm{~cm}$, composta predominantemente pelos gastrópodes terrestres Megalobulimus sp e Thaumastus sp, seguidos por moluscos marinhos Astraea sp, Strombus costatus (muitos com marcas de trabalho) e Pinctada imbricata. São encontrados também ossos de peixe e espiculas de ouriço. Dos artefatos, se destacam as pontas ósseas. A parte mais compacta desta camada foi datada em $1.533 \pm 31$ anos AP (Angulo et al. 2007: 4); e

6a Camada de coloração marrom escura, mais arenosa, com espessura média de $60 \mathrm{~cm}$. A cerca de $90 \mathrm{~cm}$ de profundidade, nas duas trincheiras, observa-se que a camada malacológica é substituída por uma nova camada que se caracteriza por apresentar pouco material arqueológico, sempre concentrado e associado às fogueiras e às áreas de lascamento de quartzo, de material lítico vulcânico e a carapaças cortadas de Strombus costatus. Na trincheira F, nos setores $\mathrm{F} 3 \# 1 \mathrm{~A}$ e $\mathrm{B}$, um verdadeiro piso formado por grandes blocos de pedras a separa da camada malacológica. As áreas de lascamento ocorrem principalmente no local da trincheira NT que está relacionada à periferia do sítio.

$\mathrm{Na}$ sexta camada também são encontrados bivalves marinhos ausentes nas camadas mais recentes, tais como Callista sp e Lucina pectinata. O material faunístico é composto predominantemente por ossos de peixe de médio e grande porte. Muitos ossos são encontrados ainda articulados, principalmente os de elasmobrânquios e de cetáceos. A maior parte das fogueiras foi 
cercada por blocos de pedra. É provável que os enterramentos encontrados a partir da profundidade de 1,30 m estejam relacionados a essa camada, sua deposição indica que foram depositados em covas de $40 \mathrm{~cm}$ de profundidade. A base desta camada está datada em cal. $3.390 \mathrm{AP}$.

\section{Sítio Ilha do Cabo Frio}

O sitio Ilha do Cabo Frio está localizado sobre duna estável coberta por outra duna mais recente. Parte dele está submerso. A parte emersa compreende três grandes manchas contendo material arqueológico espalhado numa área de $400 \mathrm{~m}^{2}$. Seu ponto mais alto fica a 20,66 $\mathrm{m}$ acima do nivel médio do mar atual.

É bem provável que o local de uma das manchas, na época em era ocupado, estivesse à beira de um córrego atualmente inexistente. É neste local que se encontra uma área plana, onde o material arqueológico está mais concentrado e relacionado a estruturas. Esse ponto, onde foram realizadas as escavações, fica cerca de $6 \mathrm{~m}$ acima do mar e dista $50 \mathrm{~m}$ da maré média atual. A parte profunda da área submersa do sitio está a 3,88 m (Calippo et al. 2005: 77). Uma amostra coletada a $1 \mathrm{~m}$ de profundidade foi datada em cal. 2.350 AP (Tabela 1).

O sítio apresenta duas camadas: uma camada malacológica, com $9 \mathrm{~cm}$ de espessura média e, abaixo desta, outra camada compacta marrom arenosa. A camada malacológica é composta por carapaças de moluscos com predominio de Pinctada imbricata e Astraea tecta olfersii (Philippi 1846), ossos de peixes e artefatos ósseos e liticos. Foi encontrada grande quantidade de pontas ósseas elaboradas a partir de esporões de raia, de peixes não identificados e, em bem menor quantidade, de aves. Dos artefatos, também cabe ressaltar a presença de dentes de tubarão perfurados. Do material litico, destacam-se as lascas, os blocos e os fragmentos de quartzo. Foi também encontrada uma estrutura calcinada repleta de ossos humanos queimados, sugerindo uma área de cremação (Fig. 8). Sua idade é de cal. 1.540 AP (Tabela 1). Próximo à estrutura de ossos calcinados foram encontrados nove fragmentos de cerâmica pertencentes à Tradição Una.

Tabela 1

\begin{tabular}{|c|c|c|c|c|c|}
\hline \multicolumn{6}{|c|}{ Datações disponíveis para os sítios trabalhados } \\
\hline Sítio & $\begin{array}{c}\text { Datações } \\
\text { convencionais }\end{array}$ & $\begin{array}{c}\text { Datação } \\
\text { calibrada } 2 \text { sigm }\end{array}$ & $\begin{array}{c}\text { Datação calibrada } \\
\text { interseção }\end{array}$ & Nivel & Laboratório \\
\hline \multirow[t]{2}{*}{ Ponta da Cabeça } & $2080 \pm 40 \mathrm{AP}$ & 2107 a 1884 AP & $2107 \mathrm{AP}$ & $70-80 \mathrm{~cm}$ & Gif $-11044^{1}$ \\
\hline & $3270 \pm 70 \mathrm{AP}$ & 3610 a 3335 AP & 3450 AP & $160-170 \mathrm{~cm}$ & Beta -84332 \\
\hline \multirow[t]{2}{*}{ Condomínio do Atalaia } & $1680 \pm 40 \mathrm{AP}$ & 1620 a $1400 \mathrm{AP}$ & $1560 \mathrm{AP}$ & $40-50 \mathrm{~cm}$ & Beta -84333 \\
\hline & $4190 \pm 130 \mathrm{AP}$ & 5035 a 4405 AP & $4820 \mathrm{AP}$ & $90-100 \mathrm{~cm}$ & Beta -95597 \\
\hline \multirow[t]{2}{*}{ Sep. Q10BE2\# } & $4120 \pm 110 \mathrm{AP}$ & 4865 a $4350 \mathrm{AP}$ & & $80-90 \mathrm{~cm}$ & Beta - 95559 \\
\hline & $1690 \pm 90 \mathrm{AP}$ & & $1530 \mathrm{AP}$ & $40-50 \mathrm{~cm}$ & Beta -235024 \\
\hline \multirow{3}{*}{ Usiminas } & $1503 \pm 31 \mathrm{AP}$ & & & $40-50 \mathrm{~cm}$ & $\wedge 14$ CHONO Centre ${ }^{* 2}$ \\
\hline & $1533 \pm 31 \mathrm{AP}$ & & & $45.50 \mathrm{~cm}$ & $\wedge 14$ CHONO Centre* \\
\hline & $3180 \pm 40 \mathrm{AP}$ & $3340-3470$ AP & 3390 AP & $130-140 \mathrm{~cm}$ & Beta -205960 \\
\hline \multirow{2}{*}{$\begin{array}{c}\text { Osso de baleia } \\
\text { NT }\end{array}$} & $2440 \pm 40 \mathrm{AP}$ & $2350-2710 \mathrm{AP}$ & $2470 \mathrm{AP}$ & $130-140 \mathrm{~cm}$ & Beta - 235047 \\
\hline & $3060 \pm 50 \mathrm{AP}$ & $3280-3330 \mathrm{AP}$ & $3280 \mathrm{AP}$ & $170-190 \mathrm{~cm}$ & Beta -257908 \\
\hline \multirow{4}{*}{$\begin{array}{l}\text { Ilha de Cabo Frio } \\
\text { ICF Submerso } \\
\text { Ilha de Cabo Frio } \\
\text { Cremação }\end{array}$} & $1630 \pm 100 \mathrm{AP}$ & $1720-1300 \mathrm{AP}$ & $1520 \mathrm{AP}$ & $90-100 m$ & Beta - 205959 \\
\hline & $2360 \pm 40 \mathrm{AP}$ & $2360-2340 \mathrm{AP}$ & $2350 \mathrm{AP}$ & $1 \mathrm{~m}$ subm. & Beta -243864 \\
\hline & $2219 \pm 32 \mathrm{AP}$ & & & $90-100 \mathrm{~cm}$ & ^14 CHONO Centre* \\
\hline & $1640 \pm 40 \mathrm{AP}$ & $1610-1420 \mathrm{AP}$ & $1540 \mathrm{AP}$ & superficie & Beta 222741 \\
\hline Boqueirão & $1623 \pm 32 \mathrm{AP}$ & & & $20-30 \mathrm{~cm}$ & $\wedge 14$ CHONO Centre * \\
\hline
\end{tabular}

(1) Datação fornecida por Rita Scheel-Ybert (1998: 112).

(2) Datações fornecidas por Rodolfo Angulo et al. (2007: 4). 


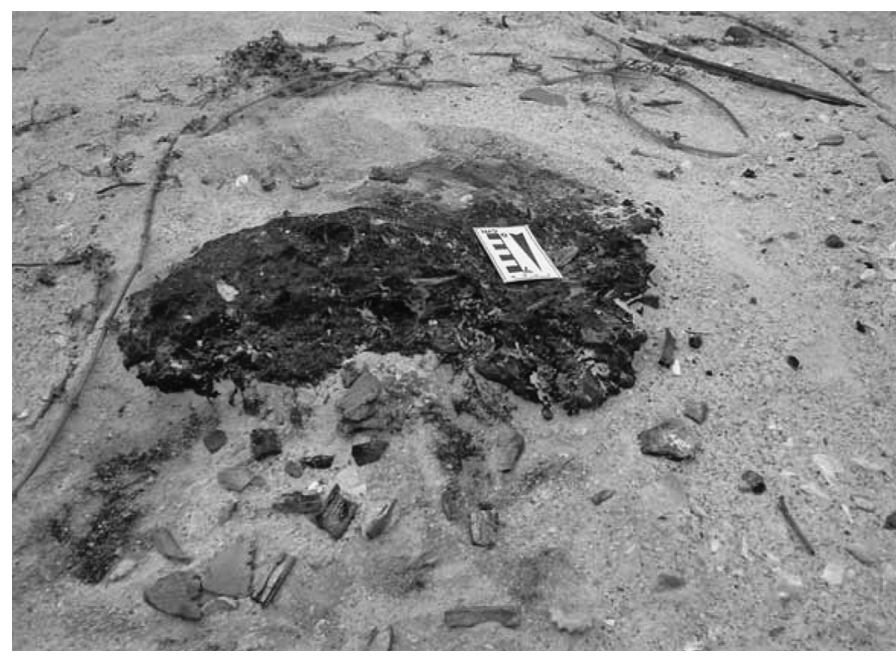

Fig. 8. Estrutura de cremação.

A análise dos restos faunísticos ainda não foi concluída; porém, os resultados alcançados até o momento estão indicando que os alimentos consumidos eram obtidos, predominantemente, no costão existente no lado da ilha voltado para o canal.

Embora as duas amostras de carvão tenham sido coletadas na base do sítio, as datações obtidas apresentaram uma amplitude de mil anos (2.219 \pm 32 e $1.242 \pm 31$ anos AP). Provavelmente o sítio foi ocupado entre 2.200 a 1.200 anos antes do presente.

\section{Considerações finais}

A proximidade das datas de inicio da formação dos sítios Usiminas (cal. 3.390 AP) e Ponta da Cabeça (cal. $3.450 \mathrm{AP}$ ) remete à questão se teriam sido construídos pelo mesmo grupo, que teria chegado ao Arraial do Cabo nesta época, quando estavam ativos os sítios do Forte, Salinas Peroano e Boca da Barra, localizados no canal de Itajuru, no Cabo Frio.

Comparando a cultura material presente nas camadas mais antigas e contemporâneas desses sitios, constata-se que as duas camadas apresentam pouco material. Os dois sitios se caracterizam por serem constituidos de fogueiras isoladas. Em relação ao material faunístico, embora ocorra um predomínio das mesmas espécies malacológicas - a

Pinctada imbricata e a Astraea tecta olfersii -, existe uma diferença relacionada a duas espécies transformadas em artefatos: a Olivancillaria sp, cuja carapaça é encontrada perfurada em grande número no Ponta da Cabeça, é ausente no sítio Usiminas. Por outro lado, as carapaças cortadas de Strombus costatus - presença marcante na camada mais antiga do sítio Usiminas -, só ocorrem nos momentos mais recentes da ocupação do sitio Ponta da Cabeça.

Com exceção do fato de que as únicas lâminas de machado encontradas nos dois sitios estavam nas camadas mais antigas, não existem elementos que indiquem que os dois sitios tenham sido formados pelo mesmo grupo. No Usiminas, uma lâmina estava associada a um enterramento e no sítio Ponta da Cabeça, provavelmente, duas também estavam associadas a enterramentos, já que próximo a elas foram encontrados dois sepultamentos em áreas muito alteradas. No entanto, a ausência de lâminas de machado não é um bom indicador, pois elas são os objetos preferidos dos colecionadores de peças arqueológicas. $\mathrm{O}$ fato de que os elementos marcantes dos momentos iniciais - as carapaças cortadas de Strombus costatus e a Olivancillaria sp perfuradas - não estão presentes nos dois sítios, reforça a constatação de que não há evidências consistentes que unam culturalmente os primeiros construtores dos sítios Usiminas e Ponta da Cabeça. Tanto o Usiminas pode ter sido iniciado através de incursões de grupos que se fixavam também no Ponta da Cabeça, como podem ter ocorrido duas ocupações concomitantes de grupos que chegaram mais ou mesmo na mesma época ao Arraial do Cabo.

Ao mesmo tempo, chama a atenção o fato de que, com exceção dos sitios sobre dunas instáveis que não possuem estratigrafia, todos os outros localizados no Arraial do Cabo se iniciam através de pequenas incursões que 
deixam fogueiras por testemunho. Só depois de algum tempo, em muitos casos mais de 1.000 anos, ocorre um grande aumento de material arqueológico, sempre associado ao surgimento de uma camada malacológica.

As incursões à Ilha do Cabo Frio poderiam ter sido motivadas por três motivos: falta, no continente, de locais com interseção ambiental e grande disponibilidade de recursos alimentares; a necessidade de ampliação de território de grupos com especialidade exploratória de ambiente insulares; ou busca por locais mais protegidos.

Com o nivel do mar mais baixo, o banco de areia que liga o continente à ilha até os dias de hoje ficaria exposto permanentemente. No estudo do material encontrado submerso relacionado ao sitio Ilha do Cabo Frio ainda não foi possivel esclarecer se se trata de material transportado ou se uma parte do sitio encontra-se atualmente submersa, o que confirmaria um momento com nivel do mar mais baixo e o afloramento de uma ponte unindo a ilha ao continente.

A existência de enterramentos na base do sitio poderia indicar que o sitio Usiminas teria sido inicialmente ocupado com intenção de ser um local destinado a sepultamentos. No entanto, a presença de um corpo d'água atrás da área do sítio, verificada na análise de sedimento (Tenório e Villagran 2009: 114), contestou a primeira interpretação ao indicar que a escolha do local se deu pelo atrativo da água doce, pouco presente na região.

A data de cal. $3.280 \mathrm{AP}$, obtida na beira do platô onde se localiza o sítio, indica que foi construido sobre uma duna escalonar que já estaria formada nesse momento. É provável que a duna estivesse represando uma lagoa temporária atrás da área do sítio, o que ainda costuma ocorrer em outros locais da ilha. A consolidação da duna, provocada pela deposição de material orgânico, teria tornado permanente $o$ corpo d'água, incentivando o estabelecimento no local.

A deposição, em dois casos, do morto em posição hiperfletida, como também a inclinação dos corpos e a diferença entre as datas obtidas na camada dos enterramentos (cal.
3.390 AP) e a obtida em um acompanhamento funerário (cal. 2.470 AP) também colocam em dúvida a função inicial do sítio Usiminas como local de enterramento.

No entanto, uma análise da cultura material presente nos sítios e um confronto com a encontrada na Ilha Grande indicam uma unidade cultural regional que se expressa pela recorrência dos mesmos hábitos alimentares e uma troca de informação e adesão dos mesmos implementos tecnológicos (Tabela 2).

\section{Conclusão}

As datações obtidas até o momento indicam que o sítio Condomínio do Atalaia teria sido a primeira ocupação pré-colonial no Arraial do Cabo, a $4.190 \pm 130$ anos AP, quando, segundo dados fornecidos por Turcq et al. (1999: 41), a restinga externa provavelmente ainda não teria se formado e o Morro do Atalaia teria uma configuração insular. Estudos recentes realizados na região confirmam que, mesmo já se encontrando num período regressivo, naquela época o nivel do mar ainda estava acima do atual (Dias 2009: 130).

A formação desse sitio em local inóspito - longe da água potável e de qualquer fonte de alimento; em local de pouca proteção dos ventos fortes, que ocorrem na região; a 55 metros acima do nível do mar e, ao mesmo tempo, com a presença de pisos de argila com buracos de estacas e manchas de fogueiras que pareciam ter sido constantemente varridas, associadas a enterramentos - sugere uma função ritual. Embora exista diversidade de moluscos marinhos, não são abundantes e são de pequeno porte, o que contribui para a interpretação de acompanhamento ritual. É provável que a ocupação mais antiga do sitio do Condomínio do Atalaia esteja associada aos construtores do sitio Salinas Peroano, localizado a cerca de $20 \mathrm{~km}$ por linha de praia, e que teve o início de sua ocupação datada em $4.340 \pm$ 70 AP. Além das datas, a presença de espátulas ósseas nos dois sítios corrobora essa hipótese. 


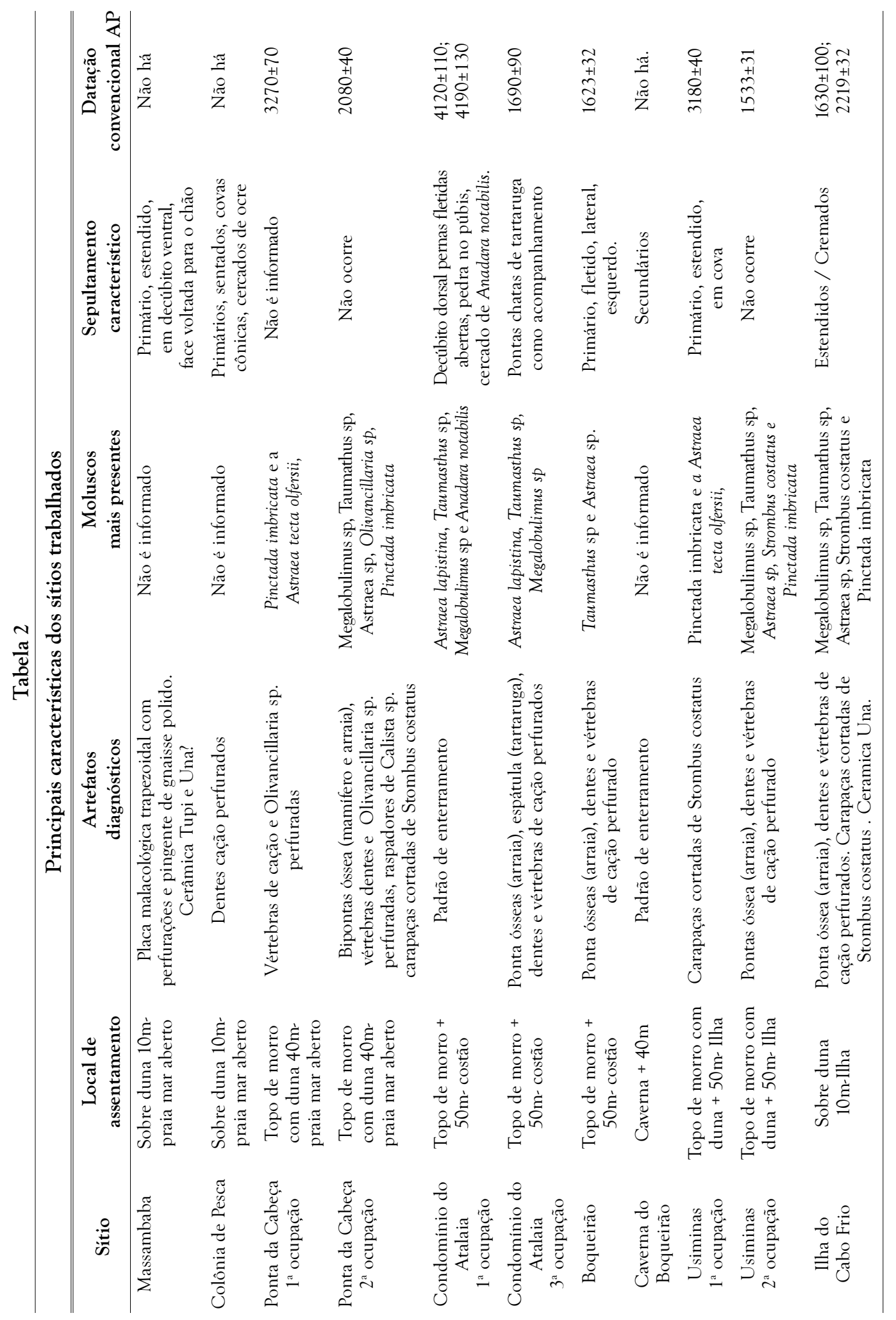


Posteriormente, cerca de 1.000 anos mais tarde, há $3.270 \pm 70$ anos AP (cal. 3.450 AP), inicia-se a ocupação do Sítio Ponta da Cabeça. É também nesse momento que se inicia a ocupação do sítio Usiminas, na Ilha do Cabo Frio. Neste periodo estavam ativos os sítios do Forte, Salinas Peroano e Boca da Barra, localizados no canal de Itajuru, no Cabo Frio.

No sitio Usiminas, a deposição, em dois casos, do morto em posição hiperfletida, a inclinação dos corpos e a diferença entre as datas obtidas na camada dos enterramentos (cal. 3.390 AP) e a obtida em um acompanhamento funerário (cal. 2.470 AP) sugerem que os sepultamentos foram feitos em covas abertas num momento posterior ao início da construção do sítio. Mais datações, tendo por amostras ossos humanos, poderão testar essas hipóteses.

Por volta de $2.080 \pm 40$ (cal. 2.107 AP), a população do Ponta da Cabeça aumentou consideravelmente e passou a ocupar toda a encosta do morro, alcançando as dunas existentes na praia de Massambaba. É também nesse momento que se firma o estabelecimento na Ilha do Cabo Frio, começando a formação do sitio da Ilha do Cabo Frio e se intensificando a ocupação do sítio Usiminas.

Mais tarde, há $1.690 \pm 90 \mathrm{AP}$ (cal. 1.560 AP), após ter sido, durante algum tempo, local de retirada e do processamento do quartzo hialino pelos habitantes do sítio Ponta da Cabeça, o sítio Condomínio do Atalaia volta a ser usado para enterrar os mortos. Nessa ocupação, os pisos de argila e as valvas de Anadara notabilis associadas aos enterramentos deixam de estar presentes e outros padrões passam a ser adotados, como o enterramento em covas, a cremação e a deposição de blocos de pedra e o acendimento de fogueiras junto ao morto. É também dessa época a cremação encontrada no sitio Ilha do Cabo Frio (1.640 \pm 40 AP; cal. 1.540 AP). O surgimento deste tipo de ritual funerário pode estar relacionado com um contato com grupos Jê, hipótese corroborada pela presença de cerâmica Una próxima à estrutura de cremação. É também nesse momento $(1.623 \pm 32 \mathrm{AP})$ que o sítio do Boqueirão começa a ser construido, a 53 metros de altura - num primeiro momento provavelmente relacionado à realização de rituais -, e que o sítio Usiminas (1.503 \pm 31 anos AP) tem sua população ainda mais aumentada.

É provável que o aumento da população percebido estivesse relacionado com a chegada de grupos Tupi ao litoral do Rio de Janeiro, cuja data foi recuada para $2600 \mathrm{AP}$ (Buarque et al. 2003: 50). É possivel trabalhar com a hipótese de que essa concentração de pessoas poderia indicar uma estratégia defensiva a grupos adventícios, quando outros grupos abandonam seus assentamentos e passam a se concentrar no Arraial do Cabo, local que apresenta pontos mais seguros e pesca abundante, graças à presença do fenômeno da Ressurgência. Andrade Lima (1991: 638) também leva em consideração a possibilidade de ter havido uma mudança no padrão de assentamento com a chegada dos ceramistas ao litoral e propõe que a ocupação da Ilha de Santana, localizada no litoral norte do estado, local mais protegido e com menor oferta de alimentos, pode ter sido consequência desse contato.

No entanto, a cerâmica encontrada nos sítios relacionados a pescadores, no Arraial do Cabo, indica que o contato com ceramistas tenha sido com grupos Jê. É provável que os Jê também estivessem fugindo da expansão Tupi e sendo empurrados para territórios ocupados por grupos litorâneos, a eles se mesclando. Se isto for confirmado, se poderá trabalhar com a hipótese de que a estrutura social sambaquiana não suportou o adensamento populacional provocado pela chegada dos Tupi ao litoral e que, no contato com os Jê, foram percebidas e adotadas novas modalidades adaptativas que descaracterizaram a cultura sambaquiana, estruturada na identificação com o mar e na exploração marinha.

Os dados obtidos indicam um início de ocupação semelhante nos sítios Ponta da Cabeça e Usiminas, através de breves incursões testemunhadas por fogueiras isoladas contendo material faunístico.

A presença de blocos de pedras junto aos enterramentos nos sítios Boqueirão, Condomi- 
nio do Atalaia e Usiminas sugere que estruturas de pedras faziam parte do ritual de enterramento predominante no Arraial do Cabo.

Com os dados obtidos, pode-se concluir que:

1) Os sítios Usiminas e Ilha do Cabo Frio, encontrados na Ilha do Cabo Frio, estão relacionados a uma única ocupação;

2) O periodo de ocupação da ilha corresponde a um periodo de adensamento populacional no Arraial do Cabo;

3) O aumento populacional do Arraial do Cabo e a ocupação da ilha podem estar relacionados à chegada de populações Tupi no litoral do estado do Rio de Janeiro;

4) Embora a pesca fosse abundante no Arraial do Cabo, isso não ocorria em relação aos moluscos. Para superar a escassez, espécies terrestres foram adicionadas à dieta alimentar e posteriormente outra espécie, a Pinctada imbricata, foi introduzida no cardápio;

5) O momento da ocupação da ilha pode ser visto como um momento de crise, dado o grande número de enterramentos de crianças verificado;

6) A presença da Pinctada imbricata na ilha pode também ter sido um dos atrativos para sua ocupação; e

7) A proximidade de água pode ter sido um dos atrativos para a ocupação do local do sitio Usiminas.

Esses resultados parecem indicar que a ocupação da Ilha do Cabo Frio foi consequência de um déficit e/ou de uma situação de emergência. No entanto, esta não pode ser a única explicação para a ocupação das ilhas e este fato não deve ser generalizado para responder à questão do isolamento e/ou do caráter intencional das ocupações insulares. Há casos, como o da Ilha Grande, em que a grande concentração de sítios na parte oceânica da ilha, onde o acesso é mais difícil, sugere que foram priorizados locais voltados para o alto mar.

As pesquisas desenvolvidas no sítio Ilhote do Leste (Tenório 2003), único sítio encontrado na Ilha Grande com expressivas camadas de ocupação, permitiram propor que lá seria um local de congregação de pessoas e um centro de dispersão de lâminas de machado.
Os resultados das pesquisas desenvolvidas na Ilha Grande e sua comparação com a cultura material encontrada nos sitios localizados no litoral sul do estado do Rio de Janeiro permitiram propor que a ilha foi ocupada por pescadores-coletores, exímios canoeiros que tinham alta mobilidade na costa. A similaridade encontrada na cultura material parece indicar grande dispersão do conhecimento tecnológico e de elementos rituais, o que sugere que a vida no litoral foi viabilizada por um grau crescente de mobilidade, de contato e de trocas. Os problemas relacionados à falta de previsibilidade e à sazonalidade da pesca, à escassez e ao esgotamento dos produtos previsiveis provavelmente teriam sido sanados pelo intenso contato e pela exploração conjunta do ambiente, o tipo de economia e de organização social característicos de grupos pescadores, verificados, ainda hoje, entre grupos caiçaras.

Os traços culturais compartilhados entre os habitantes do Arraial do Cabo e os responsáveis pela construção de sitios localizados no canal de Itajuru (Salinas Peroano e Boca da Barra) e na praia de Geribá, em Armação dos Búzios (sitio Geribá I), que foram apresentados no texto, e a existência de conjuntos de amoladores-polidores fixos semelhantes aos encontrados na Ilha Grande exemplificam essa proposta.

Em relação à discussão relacionada ao caráter insular e à intencionalidade da ocupação de ilhas, mesmo que tenha sido constatado que a ocupação da Ilha do Cabo Frio tenha sido consequência de uma expansão ou de uma estratégia defensiva, a existência de casos como o do sitio Ilhote do Leste, na Ilha Grande, e o início da construção dos sítios dos sítios Ponta da Cabeça, Condomínio do Atalaia, Salinas Peroano, Boca da Barra e Geribá II ${ }^{3}$ em locais

(3) O sitio Geribá II (Tenório et al. 1990), embora não tenha sido mencionado no texto, fica ao lado do sítio Geribá I, a 20 km de distância do Arraial do Cabo medida pela linha de praia. Está localizado sobre um embasamento rochoso e sua base foi datada em $5.150 \pm 110$ anos AP, provavelmente antes da formação da restinga que une essa ponta ao continente (Tenório et al. 2009: 88). 
isolados que poderiam estar separados do continente na época do inicio de sua ocupação corrobora as hipóteses da existência de embarcações em épocas recuadas e da intencionalidade na ocupação de ilhas.

\section{Agradecimentos}

A Jorge Marcello Filho, Márcia Barbosa, Débora Rocha, Maria Dulce Gaspar,
Teresa Portella, Carla de Moraes Ribeiro, Renata Nunes, Renata Verdun, Anderson Lyrio, Claudia Rodrigues-Carvalho, Pedro Castilho, José Paulo Jacob, Manoel Mateus Bueno Gonzalez, Flávio Rizzi Calippo, Sandra Nami Amenomori e Fernandes de Souza Filho pela participação nos trabalhos de campo. Ao IEAPM, pelo transporte maritimo. A David Canabarro, pelas informações sobre a geologia da ilha e pelo apoio logistico.

TENÓRIO, M.C.; AFONSO, M.C.; PINTO, D.C. Arraial do Cabo Archaeology, focusing on sites at Cabo Frio Island. Revista do Museu de Arqueologia e Etnologia, São Paulo, 20: 127-145, 2010.

Abstract: Arraial do Cabo, State of Rio de Janeiro, has a remarkable set of archaeological sites, drawing attention for their density and diversity in terms of settlement choices. These sites are located at dunes, open sea shores, lagoons, locations higher than 50 meters over sea level, rockshelters, islands and small bays. The characteristics of each site and the history of their occupation are discussed, with the objectives of understanding if there is a relationship between the occupation of different environments and the existence of different cultural unities, as well as the dynamics of spatial occupation, inter-site relationships and the reasons for the high concentration of sites in the research area.

Keywords: Shell mounds - Arraial do Cabo - Material culture - Contacts - Exchanges.

\section{Referências bibliográficas}

ANDRADE LIMA, T.

1991 Dos Mariscos aos Peixes: um Estudo Zooarqueológico da Mudança de Subsistência na Pré-História do Rio de Janeiro. Tese de Doutorado em Arqueologia. Faculdade de Filosofia, Letras e Ciências Humanas - Universidade de São Paulo, São Paulo.

ANGULO, R.J., REIMER, P.J.; SOUZA, M.C.; SCHEEL-YBERT, R., TENÓRIO, M.C.; DISARÓ, S.T.

2007 A tentative to determine upwelling influence on the paleo-surficial marine water reservoir effect southeastern Brazil. Radiocarbon, 49 (3), Arizona: 1-5.
BARBOSA, D.R.

1999 A Interação da População Pré-histórica do Sambaqui Boca da Barra (Cabo Frio, RJ) com o Ambiente. Dissertação de Mestrado em Ciências Ambientais. Programa de Pós-Graduação em Ciência Ambiental da Universidade Federal Fluminense, Niterói.

BARBIÉRE, E.B.

1984 Cabo Frio e Iguaba Grande, dois microclimas distintos a um curto intervalo de tempo. In: Lacerda, L.D.; Araujo, D.S.D.; Cerqueira, R.; Turcq, B. (Eds.) Restingas: origem, estrutura, processos. Niterói: CEUFF: 3-13. 
BUARQUE, A.

1999 A cultura tupinambá no Estado do Rio de Janeiro. In: Tenório, M.C. (Org.) Préhistória da Terra Brasilis. Rio de Janeiro: EDUFRJ: 307-320.

BUARQUE, A; RODRIGUES-CARVALHO, C.; SILVA, E.C.

2003 Programa Funerário dos Tupinambá em Araruama. Revista do Museu de Arqueologia e Etnologia, 13: 39-55.

CALIPPO, F.R.; TENÓRIO, M.C.; SAVI, D.C.; GONZALEZ, M.M.B.; TOLEDO, F.A.L.; VALENTE, R.C.; AFONSO, M.C.

2005 As evidências arqueológicas submersas do sambaqui da Ilha do Cabo Frio I, Arraial do Cabo - RJ. In: XIII Congresso da Sociedade de Arqueologia Brasileira, 2005. Arqueologia, Patrimônio e Turismo. Resumos. Campo Grande: 77.

CARVALHO, W.F.

2000 Produção Bacteriana e Fitoplanctônica da região de ressurgência de Arraial do Cabo, RJ. Dissertação de Mestrado em Biologia Marinha. Universidade Federal Fluminense, Niterói.

DIAS, F.F.

2009 Variações do Nivel Relativo do Mar na Planície Costeira de Cabo Frio e Armação dos Búzios, RJ. Reconstrução Paleoambiental Holocênica e Cenários Futuros. Tese de Doutorado em Geologia. Universidade Federal do Rio de Janeiro, Rio de Janeiro.

FRANCO, T.C.B.; GASPAR, M.D.

1992 O sitio arqueológico Salinas Peroano. In: Anais da VI Reunião Científica da Sociedade de Arqueologia Brasileira. Rio de Janeiro: 162-171.

FERRARI, A.L.

2001 Evolução tectônica do Gráben da Guanabara. Tese de doutorado. Instituto de Geociências - Universidade de São Paulo, São Paulo.

GURGEL, A.

1992 Valorizando a Cultura Popular. Municipios em Destaque, 46: Arraial do Cabo, RJ. Edição Especial de Aniversário: 26-28.

KNEIP, L.M.; MACHADO, L.C.

1993 Os ritos funerários das populações préhistóricas de Saquarema, RJ: sambaquis da Beirada, Moa e Pontinha. Documento de Trabalho $\mathrm{n}^{\circ} 1$. Série Arqueologia. Museu Nacional, UFRJ, Rio de Janeiro: 1-76.
MACHADO, L.M.; PONS, E.; SILVA, L.

1989a Adaptação bio-cultural no litoral fluminense: os restos ósseos humanos de dois sitios arqueológicos de Arraial do Cabo, Rio de Janeiro. Dédalo, Suplemento 1; São Paulo: 429-446.

1989b Os sitios Massambaba (RJ-JC-56) e Boqueirão (RJ-JC-57), Arraial do Cabo, Rio de Janeiro. Os padrões de sepultamento. Dédalo, Suplemento 1; São Paulo: 447-454.

MENDONÇA DE SOUZA, S.M.F.; SANTOS, R.S.; SCHRAM, C.S.; MIRANDA, C.C.

1983/84 Estudos de paleonutrição em sitios-sobredunas da fase Itaipu-RJ. Arquivos do Museu de História Natural, 8-9. Universidade Federal de Minas Gerais, Belo Horizonte: 107-120.

RODRIGUES-CARVALHO, C.; TENÓRIO, M.C.; SILVA, E.C.; LIRYO, A.; PINTO, D.C.

2005 Os sepultamentos do Condominio do Atalaia: uma população com saúde precária ou enterramentos seletivos? In: XIII Congresso da SAB, 2005. Arqueologia, Patrimônio e Turismo. Campo Grande: 142.

ROHR, S.J.,

1977 O sitio arqueológico Pântano do Sul SC-F-10. Florianópolis: Govêrno do Estado de Santa Catarina.

SCHEEL-YBERT, R.

1998 Stabilité de L'Écosystéme sur le littoral sud-est du Brésil à L'Holocene Supérieur (5500-1400 ans BP). Thése du Doctorat. Université Montepelllier II : Sciences et Tecniques du Languedoc. Montepellier, France.

TENÓRIO, M.C.

1992 Pesquisa arqueológica na Ilha Grande Sitio Ilhote do Leste. In: Anais da VI Reunião Cientifica da Sociedade de Arqueologia Brasileira. Vol. 1. Rio de Janeiro: 292-303.

1998 Abandonment in Brazilian coastal sites: Why leave the Eden. In: Plew, M.G.

(Org.) Explorations in American Archaeology: Essays in honor of Wesley R. Hurt. Lanham: University Press of America: 221-258.

2002 Sítio Condomínio do Atalaia: Um estudo de caso para entender porque os construtores de sambaqui acumulavam o alimento. In: Lima, T.A. (Org.) Anais da SAB, 2001. A Arqueologia do Novo Milênio. Rio de Janeiro. CD-Rom.

2003 O Lugar dos Aventureiros: identidade, 
dinâmica de ocupação e sistema de trocas no litoral do Rio de Janeiro há 3500 anos antes do presente. Tese de Doutorado. Programa de Pós-Graduação em História da Faculdade de Filosofias e Ciências Humanas da Pontificia Universidade Católica do Rio Grande do Sul - PUCRS.

TENÓRIO, M.C.; GASPAR, M.D.

1990 Amoladores e polidores fixos do litoral brasileiro. In: Anais da V Reunião Cientifica da Sociedade de Arqueologia Brasileira Revista do CEPA, 17: 181-190.

TENÓRIO, M.C.; GASPAR, M.D.; BULCÃO, S.

1990 Pesquisas arqueológicas na praia de Geribá. In: Anais da V Reunião Cientifica da Sociedade de Arqueologia Brasileira. Revista do CEPA, Santa Cruz do Sul, 17: 221-258.

TENÓRIO, M.C.; GUIMARÃES, M.; PORTELLA, T.

1992 O sítio Ponta da Cabeça, Arraial do Cabo, Rio de Janeiro. In: Anais da VI Reunião Cientifica da Sociedade de Arqueologia Brasileira. Vol 1. Rio de Janeiro: 279-291.

TENÓRIO, M.C.; AFONSO, M.C.; SAVI, D.; PINTO, D.C.; GONZALEZ, M.M.B.; AMENOMORI, S. N.; ANGULO, R.

2005 O sítio ou os sitios da Ilha do Cabo Frio: Primeiros resultados. In: XIII Congresso da Sociedade de Arqueologia Brasileira, 2005. Resumos. Campo Grande: 51.

TENÓRIO, M.C.; PINTO, D.C.; AFONSO, M.C.

2009 Dinâmica de ocupação, contatos e trocas no litoral do Rio de Janeiro. Arquivos do Museu Nacional, 66: 311-321.

TENÓRIO, M.C.; VILLAGRAN, X.S.

2009 Dinâmica espacial e assentamentos domésticos nos sambaquis da Ilha do Cabo Frio (Rio de Janeiro). In: XV Congresso da Sociedade de Arqueologia Brasileira. Resumos. Belém, vol. 1: 144.

TENÓRIO, M.C.; DIAS, F.F.; CASTRO, J.W.

2009 O sítio Geribá II, Búzios - Estado do Rio de Janeiro: Registro de um Sambaqui Antigo In: XV Congresso da Sociedade de Arqueologia Brasileira. Resumos. Belém, vol. 1: 88 .

TURCQ, B.; MARTIN, L.; FLEXOR, J.L.; SUGUIO, K.; PIERRE, C.; TASAYACO-ORTEGA, L.

1999 Origin and evolution of the Quaternary coastal plain between Guaratiba and Cabo Frio, State of Rio de Janeiro. In: Knoppers, B.A.; Bidone, E.D., Abrão, J.J. (Eds.) Environmental Geochemistry of Coastal Lagoon Systems, Rio de Janeiro, Brazil. Niterói: EDUFF: 25-45 (Série Geoquimica Ambiental). 